\title{
Outcome of Four Point Fixated Open Loop Polymethyl Methacrylate Anterior Chamber Intraocular Lens: A Ten-Year Retrospective Study
}

Sonali Sahoo

LV Prasad Eye Institute

Priyadarsini Parida

LV Prasad Eye Institute

Amrita Mohanty

LV Prasad Eye Institute

Sujata Das

LV Prasad Eye Institute

Ashik Mohamed

LV Prasad Eye Institute

Srikant Sahu ( $\nabla$ srikantsahu@lvpei.org )

LV Prasad Eye Institute https://orcid.org/0000-0002-1706-5420

\section{Research Article}

Keywords: Anterior chamber intraocular lens, Cataract surgery, Aphakia, Intraocular pressure

Posted Date: June 9th, 2021

DOI: https://doi.org/10.21203/rs.3.rs-594148/v1

License: () (1) This work is licensed under a Creative Commons Attribution 4.0 International License.

Read Full License 


\section{Abstract}

\section{Purpose}

To study long term visual and refractive outcomes and complications in eyes with anterior chamber intraocular lens (ACIOL) implantation

\section{Methods}

Data of patients who underwent primary and secondary ACIOL implantation at L V Prasad Eye Institute, Bhubaneswar between 2011-2020 was collected, including details of post-operative visits. For analysis, sample was divided into: group la (primary $A C I O L$ in cases without risk factors, $n=104$ ); group lb (primary $\mathrm{ACIOL}$ in cases with pre-existing risk factors, $n=49$ ); and group II (secondary ACIOL, $n=40$ ).

\section{Results}

A total of 293 eyes of 288 patients were included. Mean pre-operative and last visit corrected distance visual acuity were $1.65 \pm 0.79$ and $0.49 \pm 0.65 \log$ MAR units in group la $(p<0.001)$, and $1.46 \pm 0.74$ and $0.52 \pm 0.72$ logMAR units in group $\mathrm{lb}(\mathrm{p}<0.001)$. The mean spherical equivalent (MSE) for last refraction was $-0.37 \pm 1.05$ dioptres $(D)$ and $-0.57 \pm 1.04 \mathrm{D}$ in groups I and II, respectively. Of 76 eyes in which addition of 2.5 $\mathrm{D}$ (over the near emmetropic posterior chamber intraocular lens power) was taken for ACIOL, 40 (52.6\%) had MSE within $\pm 0.5 \mathrm{D}$. Most common complications were transient corneal edema and anterior chamber reaction. Eyes on anti-glaucoma medications at last visit were eight (7.7\%), 15 (30.6\%), and two (5.0\%) in groups la, lb, and II respectively.

\section{Conclusions}

We observed that ACIOLs have good visual and refractive outcomes. Raised IOP is a concern in eyes with pseudoexfoliation, but can be managed with close monitoring. Hence ACIOL can be a good option for managing aphakia after cataract surgery.

\section{Introduction}

Cataract surgery followed by intraocular lens (IOL) implantation is the most commonly performed ophthalmic surgery worldwide. ${ }^{[1]}$ In the presence of adequate capsular support, IOL implantation in the anatomical position of the lens, i.e., the capsular bag, is preferred. The sulcus is the next best alternative for placement of the IOL. However, with complications such as large posterior capsular rent, zonular dialysis, removal of a subluxated cataractous lens or IOL, the surgeon has to consider alternative options such as letting the eye remain aphakic or implantation of an anterior chamber IOL (ACIOL), iris-fixated IOL, or a scleral-fixated IOL (SFIOL).

$\mathrm{ACIOL}$ insertion is a relatively simple procedure and can be planned along with cataract extraction. However, the main concerns are the potential side effects such as corneal decompensation, raised 
intraocular pressure (IOP), and cystoid macular edema. ${ }^{[2]} \mathrm{ACIOLs}$ have regained popularity as the openloop haptic design used currently has a better safety profile than the closed-loop design. ${ }^{[3,4]}$

Iris-fixated IOLs require a certain amount of surgical expertise and cannot be implanted in eyes with iris atrophy, aniridia, or in patients with bleeding diatheses. Moreover, they are associated with complications such as pigment dispersion and glaucoma. ${ }^{[5]}$

Scleral-fixated IOL, though a popular choice in management of aphakia, is technically more challenging, has a long learning curve and all cataract surgeons are not comfortable with it. ${ }^{[5]}$ SFIOLs are implanted closer to the anatomical position of lens, and thus have fewer complications but require additional surgery, which may not be feasible in all cases. ${ }^{[1]}$

This study aims to provide long-term visual outcome, safety profile, and complication rates in primary as well as secondary implantation of ACIOLs.

\section{Materials And Methods}

This was a single-centre, retrospective study conducted at L V Prasad Eye Institute, Bhubaneswar, India. The study adhered to the tenets of the Declaration of Helsinki and was approved by the Institutional Ethics Committee. Data from all patients who underwent ACIOL implantation during the period 1st July 2011 to 30th June 2020 was collected from electronic medical records.

\section{Inclusion criteria:}

Patients who underwent primary or secondary ACIOL implantation following cataract surgery

\section{Exclusion criteria:}

Patients with the following conditions were excluded from the study:

1. Combined surgery (with penetrating keratoplasty, Descemet's stripping endothelial keratoplasty, Descemet's membrane endothelial keratoplasty, trabeculectomy, or pars plana vitrectomy)

2. IOL exchange surgery

3. Pre-existing ocular pathology (adherent leucoma, optic atrophy, choroidal neovascular membrane, or retinitis pigmentosa)

4. Phacolytic or lens particle glaucoma

5. Follow-up period < 1-month post-surgery

Data collected for the study included patient demographics, pre-operative best corrected visual acuity (BCVA), intraocular pressure (IOP), grade of cataract, surgeon's experience (trainee or consultant), surgical time and intraoperative complications leading to the implantation of ACIOL. Details of post-operative 
visits at 1 day, 1 week, 1 month, 3 months, 6 months and the last visit were recorded, which included BCVA, IOP, refraction, post-operative complications if any, and their management.

\section{Surgical technique:}

After performing anterior vitrectomy, the pupil was constricted using pilocarpine. A surgical peripheral iridectomy $(\mathrm{PI})$ was performed and then a single piece polymethyl methacrylate (PMMA) open loop semiflexible lens with four-point fixation ACIOL was implanted in the anterior chamber via a $5.5 \mathrm{~mm}$ corneal/scleral incision and dialled in place. The main wound was sutured with $10-0$ nylon sutures The A constant of the ACIOL implanted was 115.3. IOL power was calculated as an addition of +1.5 to +3.00 D to the nearest emmetropia for a posterior chamber IOL (PCIOL).

\section{Post-operative regimen:}

Corneal edema was graded according to the Oxford Cataract Treatment and Evaluation Team grading system $^{[6.7]}$ (Online resource 1). Anterior chamber inflammation was graded according to the Standardization of Uveitis Nomenclature scheme for anterior chamber cells and flare ${ }^{[8]}$ (Online resource 2). Topical antibiotics and corticosteroids were prescribed post-operatively. IOP $>21$ millimetres of mercury ( $\mathrm{mm} \mathrm{Hg}$ ) was considered as raised IOP. In cases with raised IOP, topical and/or systemic antiglaucoma medications (AGM) were prescribed on a case-to-case basis.

\section{Statistical analysis:}

Data analysis was performed using the software STATA v14.2 (StataCorp, College Station, TX, USA). Continuous variables were expressed as mean \pm standard deviation or median with inter-quartile range, and categorical variables were expressed as individual counts and proportions. A linear mixed-effects model using maximum likelihood estimation with random intercepts at the patient level was used to account for the correlation between the right and left eye, and to make comparisons between the groups. The Snellen BCVA was converted into the logarithm of the minimum angle of resolution (logMAR) units for analysis. ${ }^{[9,10]}$ Analysis of refractive outcome was done by taking the spherical equivalent. A p-value of $<0.05$ was considered statistically significant.

\section{Results}

ACIOL implantation was done in 293 eyes of 288 patients over a period of 10 years (2011-2020), of which 193 eyes of 192 patients were included in the study. For analysis, the total sample was divided into three groups:

Group I: Primary ACIOL: IOL implanted at the time of primary surgery

la: without any risk factors

Ib: with Pseudoexfoliation/ Subluxation/ Traumatic cataract 
Group II: Secondary ACIOL: IOL implanted at a follow up surgery

The detailed distribution of the groups is depicted in Figure 1.

The mean age and gender distribution were similar in all three groups.

\section{Surgery details: (Table 1)}

The consultants performed $95(62.1 \%)$ and 26 (65.0\%) surgeries and the trainees performed 58 (37.9\%) and 14 (35.0\%) surgeries, in groups I and II respectively. In group I, the mean surgical time for consultants and trainees was $42.13 \pm 21.10$ minutes and $74.05 \pm 31.88$ minutes respectively $(p<0.001)$. In group II, the mean surgical time for consultants and trainees was $28.05 \pm 18.53$ minutes and $30.08 \pm 12.90$ minutes respectively $(p=0.73)$.

The mean duration between the primary and secondary surgeries in group II was 3.85 months (median 2, Interquartile range 1.625). The mean postoperative follow-up period in groups I and II were 8.6 months (median 3, Interquartile range 8 ), and 11.51 months (median 5 , Interquartile range 11.5 ) respectively.

\section{Visual outcome:}

Group I: The mean pre-operative and last visit BCVA were $1.65 \pm 0.79$ and $0.49 \pm 0.65$ logMAR units in group la $(p<0.001)$, and $1.46 \pm 0.74$ and $0.52 \pm 0.72 \log M A R$ units in group $\mathrm{lb}(p<0.001)$ (Table 1$)$.

Group II: Mean pre-operative [with +10.0 dioptres (D)] and last visit BCVA were $0.43 \pm 0.39$ and $0.35 \pm 0.41$ $\log M A R$ units, respectively $(p=0.35)$.

\section{Refractive outcome:}

Post-operative refractive outcome was available for 178 out of 193 eyes. The mean spherical equivalent (MSE) for the last refraction performed was $-0.37 \pm 1.05 \mathrm{D}$ and $-0.57 \pm 1.04 \mathrm{D}$ in groups I and II, respectively $(p=0.54)$.

Figure 2 shows the final MSE based on the addition of ACIOL power implanted. Seventy-three $(70.1 \%)$ eyes in group la, $33(67.4 \%)$ eyes in group Ib, and $26(65.0 \%)$ eyes in group II had MSE within $\pm 1.0 \mathrm{D}$ at final refraction. A refractive surprise of $>1.5 \mathrm{D}$ was seen in two $(1.1 \%)$, three $(1.7 \%)$, ten $(5.6 \%)$ and three (1.7\%) eyes, when the addition was 1.5 D, 2.0 D,2.5 D and 3.0 D, respectively.

Post-operative hyperopia (MSE>1.0 D) was noted in zero, six (3.4\%) and two (1.1\%) eyes when addition in ACIOL power taken was 2, 2.5 and $3 \mathrm{D}$ respectively.

\section{Post-operative complications:}

The early and late post-operative complications are summarised in Table 2. The incidence of various complications was not statistically significant between groups la and Ib. 
Rise in intraocular pressure: (Online resource 3)

Group la: IOP was raised in $21(20.2 \%)$ eyes on postoperative day (POD) 1. In four (3.9\%) patients, a rise in IOP was observed for the first time at post-operative period (POP) of 1 week. IOP was controlled in all eyes at the last visit. Glaucomatous disc damage was seen in one $(0.9 \%)$ eye.

Group Ib: IOP was raised in 11 (22.5\%), three (6.1\%) and 5 (10.2\%) eyes on POD 1, POP 1 week and POP 1 month, respectively. In 15 (30.6\%) eyes, IOP was under control with AGMs at the last visit. Glaucomatous disc damage was present in eight (16.3\%) eyes.

Group II: IOP was raised in five (12.5\%) and five (12.5\%) eyes on POD 1 and POP 1 month, respectively. At last visit, IOP was under control with AGMs in two (5.0\%) eyes.

The difference in IOP between groups I and II was not statistically significant after adjusting for the baseline differences between the groups (primary surgeon, surgical time, pre-existing zonular dialysis, posterior capsular rent, vitreous loss, and pre-operative IOP) (Online resource 4). The percentage of eyes in the three groups on AGMs at POP 1 month and at last visit is shown in Figure 3.

\section{Corneal edema:}

Group la: On POD 1, grade 1 corneal edema was present in 88 (84.6\%) eyes which resolved within 1 week. Grade 2 edema was present in $12(11.5 \%)$ eyes.

Group Ib: On POD 1, grade 1 corneal edema was present in 30 (61.22\%) eyes and grade 2 edema in 14 (28.6\%) eyes. All resolved subsequently.

Group II: On POD 1, grade 1 corneal edema was present in 28 (70.0\%) eyes out of which 27 resolved subsequently. Corneal decompensation was noted in one (2.5\%) eye, at POP 4 years.

Anterior chamber $(A C)$ inflammation:

Group la: Mild AC reaction (cells 0.5+, flare 1+) was seen in 100 (96.2\%) eyes on POD 1 out of which 99 resolved. Late-onset of AC inflammation (cells $1+$, flare $2+$ ) was seen in one $(0.9 \%)$ eye.

Group lb: Mild AC reaction was seen in 48 (97.96\%) eyes on POD 1. Of these, 47 resolved in 1 week.

Group II: Mild AC reaction was seen in 34 (85.0\%) eyes on POD 1 all of which resolved subsequently. AC inflammation (cells $1+$, flare $1+$ ) at POP 1 and 3 months was seen for the first time in one (2.5\%) and two (5.0\%) eyes respectively.

Cystoid macular edema (CME):

Group I: Four (3.9\%) eyes developed CME at 1 month. Four (3.9\%) eyes developed CME at POP 1. None of the patients developed CME in group Ib. 
Group II: Two (5.0\%) eyes developed CME at POP 1 year.

ACIOL explantation:

ACIOL was explanted in three (2.9\%) eyes in group la, and one (2.0\%) eye each in groups $\mathrm{Ib}$ and II. The reasons were persistent corneal edema, persistent anterior chamber inflammation, persistent raised IOP and cystoid macular edema.

\section{Discussion}

Cataract surgery, though a routine procedure for an ophthalmologist, can sometimes lead to complications resulting in the inability to implant an intraocular lens in the bag or sulcus. The chances of surgical aphakia are higher in the presence of risk factors such as pseudoexfoliation syndrome, subluxated lens, or a history of trauma, as seen in our study where the incidence of intra-operative complications such as zonular dialysis was higher in the group with these risk factors $(p<0.001)$.

The options for managing surgical aphakia include implantation of primary or secondary ACIOL, irisfixated IOL, or SFIOL. Each option has its advantages and disadvantages, and depends on the surgeon's skill and choice of IOL for implantation. In this study, we have attempted to look at the outcomes of primary and secondary implantation of $\mathrm{ACIOL}$ in cases with and without pre-existing risk factors for aphakia. The focus of our study was on the long-term outcome and the refractive outcome. A unique feature of our study, compared to other studies, is that none of the subjects underwent pars plana vitrectomy before $\mathrm{ACIOL}$ implantation, which itself is a technically demanding procedure. ${ }^{[11,12]}$

Being a training institute, our surgeons comprised of both consultants and trainees. If the case was complicated, senior trainees or consultants took over. While the consultants' surgical time was significantly shorter, the outcomes were similar for both consultants and trainees, demonstrating that a trainee can also implant an ACIOL with a good outcome, if well-trained.

Looking at the visual outcomes, the mean BCVA at final follow up was significantly better than the preoperative BCVA. This is similar to earlier studies. ${ }^{[11,13,14]}$

The refractive outcome in our study is also significant. Mean final spherical equivalent was $-0.41 \pm 1.05$ D, which was comparable with other studies. ${ }^{[11,15]}$ We also studied the relationship between the power of $\mathrm{ACIOL}$ chosen and the refractive outcome. We noted that the final MSE was within 0 to $\pm 0.5 \mathrm{D}$ in 15 (8.4\%), 40 (22.5\%) and 30 (16.9) eyes when the ACIOL was implanted with an addition of 2, 2.5 and $3 \mathrm{D}$ to the near emmetropic PCIOL power, respectively. This implies that even if an ACIOL with power $2.5 \mathrm{D}$ less than emmetropic PCIOL power (which is ideal) is not available, we can choose one that is $3 \mathrm{D}$ less, for a better refractive outcome.

The main concerns with ACIOL implantation are the complications associated with it, mainly rise in IOP, long term corneal decompensation, and CME. The incidence of all of these complications was quite low 
in our study with the use of open-loop ACIOLs, which is comparable to other studies. ${ }^{[1,12,14]}$ In cases with pre-existing pseudoexfoliation syndrome, early ocular hypertension was of concern, but that is expected due to the nature of the disease. On the same lines, this group had the highest number of eyes on AGMs at the last visit. Hence, these cases require vigilance and regular follow up. Persistent AC inflammation, raised IOP leading to corneal edema and non-resolving cystoid macular edema were the main reasons of IOL explanation in five patients. Such patients need close follow up and IOL explantation should be considered if inflammation cannot be controlled with medical management.

We also observed that secondary implantation of ACIOL has similar visual and refractive outcomes as primary implantation, with low complication rate. Therefore, secondary ACIOL implantation can be a good option in cases where primary implantation is not feasible.

A limitation to our study is the absence of specular microscopy findings post-operatively, as corneal decompensation is a major concern post ACIOL implantation. However, corneal decompensation was not a major clinical complication in our study. The retrospective nature of the study also has its inherent bias.

In summary, we found that ACIOLs have a good safety profile with good visual and refractive outcome. ACIOLs require minimal surgical expertise as compared to SFIOLs. These are a good option in eyes with pseudoexfoliation and subluxated or traumatic cataracts, with a close watch on the intra-ocular pressure. Therefore, ACIOL can be used in aphakic eyes after complicated cataract surgeries as an alternative to SFIOL.

\section{Conclusions}

We observed that ACIOLs have good visual and refractive outcomes. Raised IOP is a concern in eyes with pseudoexfoliation, but can be managed with close monitoring. Hence ACIOL can be a good option for managing aphakia after cataract surgery.

\section{Declarations}

Authors' contributions: All authors contributed to the study conception and design. Material preparation, data collection and analysis were performed by Sonali Sahoo, Priyadarsini Parida and Srikant K Sahu. The first draft of the manuscript was written by Sonali Sahoo and all authors commented on previous versions of the manuscript. All authors read and approved the final manuscript.

Funding/Conflicts of interest/Competing interests:

- The authors have no relevant financial or non-financial interests to disclose.

- The authors have no conflicts of interest to declare that are relevant to the content of this article.

- All authors certify that they have no affiliations with or involvement in any organization or entity with any financial interest or non-financial interest in the subject matter or materials discussed in this manuscript. 
- The authors have no financial or proprietary interests in any material discussed in this article.

Ethical committee approval: Taken for retrospective study

\section{References}

1. Chan TCY, Lam JKM, Jhanji V, Li EYM (2015) Comparison of outcomes of primary anterior chamber versus secondary scleral-fixated intraocular lens implantation in complicated cataract surgeries. Am J Ophthalmol 159(2):221-226.e2

2. Moschos MM, Eirini N (2016) The correction of aphakia using anterior chamber intraocular lens. In Vivo (Brooklyn) 30(6):733-738

3. Smith PW, Wong SK, Stark WJ, Gottsch JD, Terry AC, Bonham RD (1987) Complications of semiflexible, closed-loop anterior chamber intraocular lenses. Arch Ophthalmol 105(1):52-57

4. Weene LE (1993) Flexible open-loop anterior chamber intraocular lens implants. Ophthalmology 100(11):1636-1639

5. Kim EJ, Brunin GM, Al-Mohtaseb ZN (2016) Lens placement in the absence of capsular support: Scleral-fixated versus iris-fixated IOL versus ACIOL. Int Ophthalmol Clin 56(3):93-106

6. Cheng H, Mcpherson K, Bron AJ et al (1986) Use of a grading system in the evaluation of complications in a randomised controlled trial on cataract surgery. $\mathrm{Br} J$ Ophthalmol 70(6):411-414

7. Long-term corneal (1986) endothelial cell loss after cataract surgery: Results of a randomized controlled trial. Arch Ophthalmol 104(8):1170-1175

8. Jabs DA, Nussenblatt RB, Rosenbaum JT et al. Standardization of uveitis nomenclature for reporting clinical data. Results of the first international workshop. Am J Ophthalmol. 2005;140(3):509-516

9. Schulze-Bonsel K, Feltgen N, Burau H, Hansen L, Bach M (2006) Visual acuities "hand motion" and "counting fingers" can be quantified with the Freiburg Visual Acuity Test. Investig Ophthalmol Vis Sci 47(3):1236-1240

10. Schulze-Bonsel K, Feltgen N, Burau H, Hansen L, Bach M (Author Response: Numerical Imputation for Low Vision States. Invest Ophthalmol Vis Sci. Published 2007) Accessed April 26, 2021. https://michaelbach.de/sci/pubs/Bach2007IOVS_eLetter_FrACT.pdf

11. Negretti GS, Lai M, Petrou P, Walker R, Charteris D (2018) Anterior chamber lens implantation in vitrectomised eyes. Eye 32(3):597-601

12. Khan MA, Gupta OP, Pendi K et al (2019) Pars plana vitrectomy with anterior chamber versus gore-tex sutured posterior chamber intraocular lens placement: Long-Term Outcomes. Retina 39(5):860-866

13. Suelves AM, Siddique SS, Schurko B, Foster CS (2014) Anterior chamber intraocular lens implantation in patients with a history of chronic uveitis: Five-year follow-up. J Cataract Refract Surg 40(1):77-81

14. Kwong YYY, Yuen HKL, Lam RF, Lee VYW, Rao SK, Lam DSC (2007) Comparison of outcomes of primary scleral-fixated versus primary anterior chamber intraocular lens implantation in complicated 
cataract surgeries. Ophthalmology 114(1):80-85

15. David DiLoreto J (2020) Refractive outcomes of anterior chamber intraocular lens implantation. Invest Ophthalmol Vis Sci 61(7):1683-1683

\section{Tables}

Table 1 Baseline characteristics of group I (Primary ACIOL)

\begin{tabular}{|c|c|c|c|}
\hline & GROUP la $(N=104)$ & GROUP Ib $(\mathrm{N}=49)$ & P VALUE \\
\hline Mean age (years) & $68 \pm 10^{a}$ & $68 \pm 11^{a}$ & 0.77 \\
\hline $\begin{array}{l}\text { Gender } \\
\text { Male/Female }\end{array}$ & $57 / 47$ & $34 / 15$ & 0.09 \\
\hline $\begin{array}{l}\text { Grade of cataract } \\
\text { Total white or brown/Others }\end{array}$ & $45 / 59$ & $24 / 25$ & 0.62 \\
\hline $\begin{array}{l}\text { Primary surgeon } \\
\text { Consultant/Trainees }\end{array}$ & $58 / 12$ & $37 / 12$ & $0.02 *$ \\
\hline $\begin{array}{l}\text { Main reason for } \mathrm{ACIOL} \text { implantation } \\
\text { PCR } \\
\text { ZD }\end{array}$ & $\begin{array}{l}36 \\
38\end{array}$ & $\begin{array}{l}9 \\
39\end{array}$ & $\begin{array}{l}0.04^{\star} \\
<0.001^{\star}\end{array}$ \\
\hline Mean post-operative follow-up (months) & $8.75 \pm 14.27^{\mathrm{a}}$ & $8.53 \pm 14.43^{a}$ & 0.93 \\
\hline $\begin{array}{l}\text { Visual outcome (logMAR units) } \\
\text { Mean pre-operative BCVA } \\
\text { Mean final post-operative BCVA } \\
\text { Mean difference in BCVA }\end{array}$ & $\begin{array}{l}1.65 \pm 0.79^{a} \\
0.49 \pm 0.65^{a} \\
1.16 \pm 0.86^{a}\end{array}$ & $\begin{array}{l}1.46 \pm 0.74^{a} \\
0.52 \pm 0.72^{a} \\
0.94 \pm 1.02^{a}\end{array}$ & $\begin{array}{l}0.16 \\
0.75 \\
0.16\end{array}$ \\
\hline $\begin{array}{l}\text { Refractive outcome (Dioptres) } \\
\text { Mean final spherical equivalent }\end{array}$ & $-0.47 \pm 1.05^{a}$ & $-0.34 \pm 1.05^{a}$ & 0.54 \\
\hline \multicolumn{4}{|l|}{ *Statistically significant } \\
\hline \multicolumn{4}{|l|}{${ }^{\text {a }}$ Mean \pm Standard Deviation } \\
\hline $\begin{array}{l}\text { ACIOL: Anterior Chamber Intraocular Lens } \\
\text { Best Corrected Visual Acuity; logMAR: Lo }\end{array}$ & $\begin{array}{l}\text { R: Posterior Capsular } \\
\mathrm{hm} \text { of Minimum Ang }\end{array}$ & $\begin{array}{l}\text { ent; ZD: Zonular Dia } \\
\text { of Resolution }\end{array}$ & is; BCVA: \\
\hline
\end{tabular}

Table 2 Post-operative complications in group I (Primary ACIOL) 


\begin{tabular}{|llll|}
\hline COMPLICATIONS & $\begin{array}{l}\text { GROUP la \{NO. OF } \\
\text { EYES(\%)\} }\end{array}$ & $\begin{array}{l}\text { GROUP Ib \{NO. OF } \\
\text { EYES(\%) }\end{array}$ & $\begin{array}{l}\text { P } \\
\text { Early (Within 3 Months) }\end{array}$ \\
\hline 1. Rise in IOP (> 21 mm Hg) & $29(27.88)$ & $18(36.73)$ & 0.43 \\
\hline 2. Corneal Edema & $100(96.15)$ & $44(89.79)$ & 0.15 \\
\hline 3. Anterior Chamber Reaction & $100(96.15)$ & $48(97.96)$ & 0.67 \\
\hline 4. Hyphema & $9(8.65)$ & $6(12.24)$ & 0.56 \\
\hline $\begin{array}{l}\text { 5. Vitreous Prolapse in Anterior } \\
\text { Chamber }\end{array}$ & $11(10.57)$ & $5(10.2)$ & 0.52 \\
\hline 6. Cystoid Macular Edema & $5(4.8)$ & 0 & 0.18 \\
\hline 7. Retinal Detachment & 0 & $2(4.08)$ & 0.10 \\
\hline Late (After 3 Months) & $9(8.65)$ & $2(4.08)$ & 0.64 \\
\hline 1. Rise in IOP (> 21 mm Hg) & & 0 & 1.00 \\
\hline 2. Corneal Edema & 0 & 0 & 1.00 \\
\hline 3. Anterior Chamber Reaction & $1(0.9)$ & 0 & 0.28 \\
\hline 4. Cystoid Macular Edema & $4(3.8)$ & $1(2.04)$ & 1.00 \\
\hline 5. Retinal Detachment & $2(1.9)$ & & \\
\hline IOP: Intraocular Pressure; mm Hg: Millimetres of Mercury & & \\
\hline
\end{tabular}

\section{Figures}




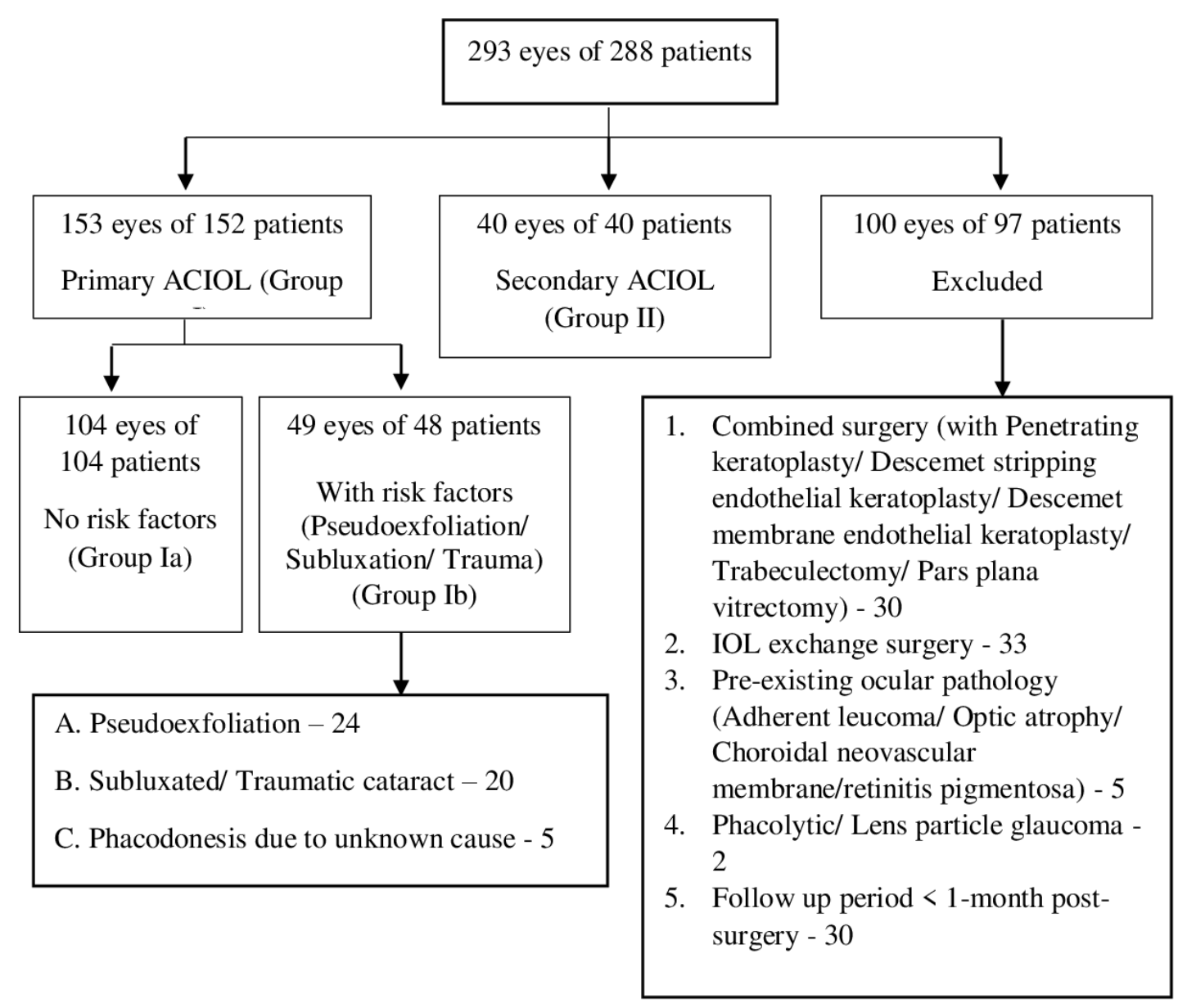

\section{Figure 1}

Flowchart showing detailed sub-group division of the study sample ACIOL: Anterior Chamber Intraocular Lens; IOL: Intraocular Lens 


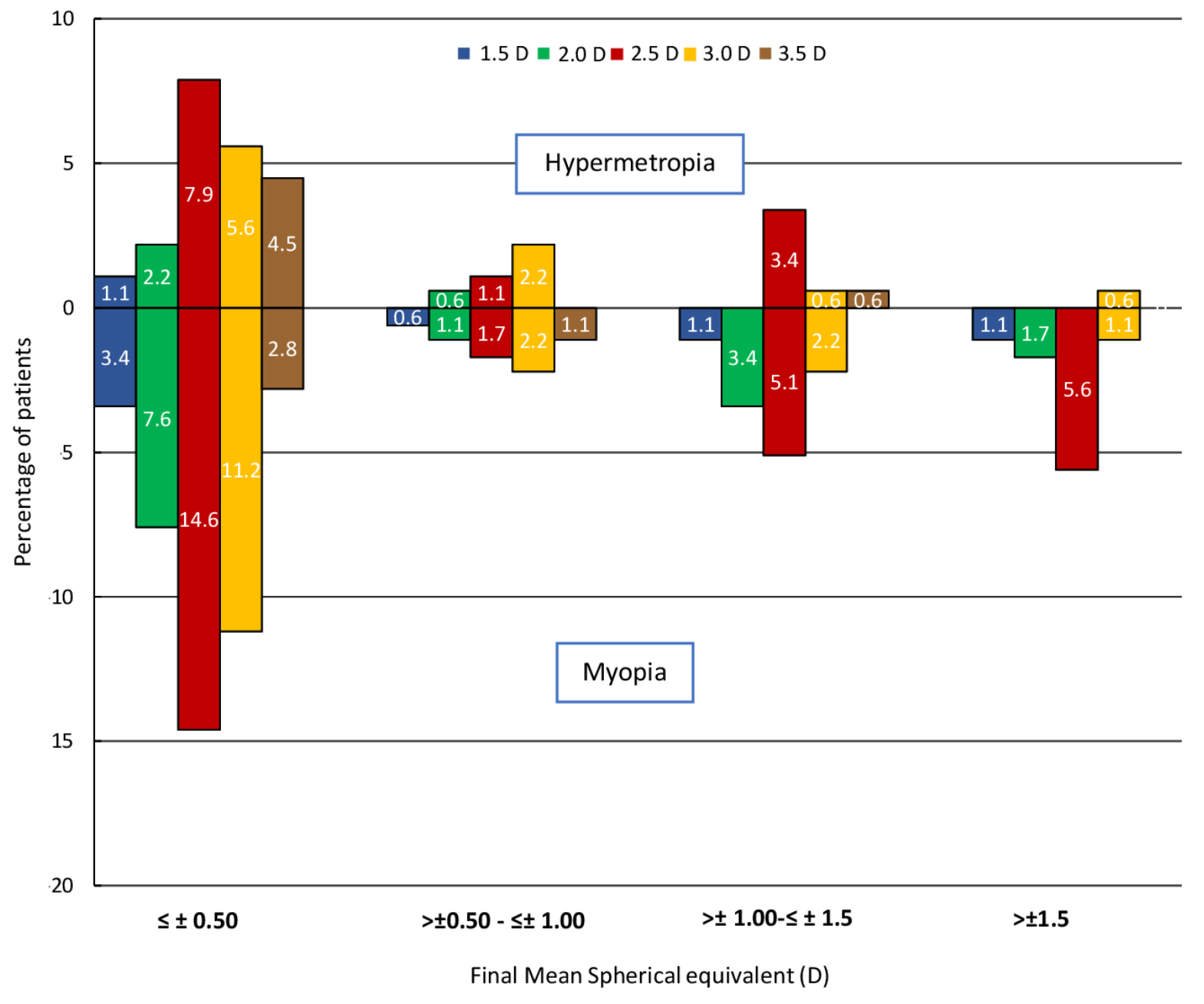

Figure 2

Mean Spherical Equivalent of final refraction as per the Anterior Chamber Intraocular lens power (addition over the near emmetropic posterior chamber intraocular lens power - represented by the coloured bars) implanted. The bars above the horizontal zero axis denote hypermetropic error and those below the axis denote myopic error. D: Dioptre 

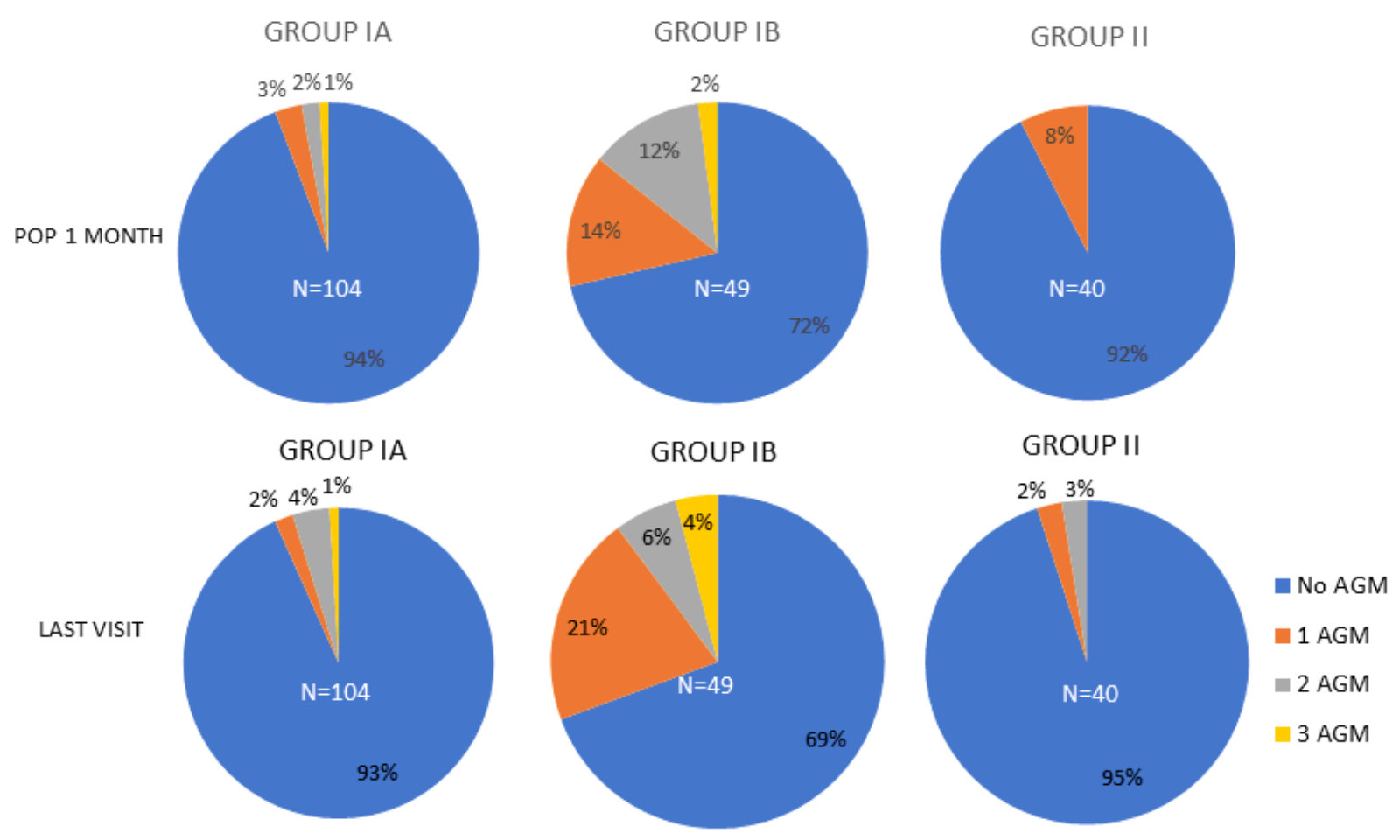

\section{Figure 3}

Percentage of eyes in each group on Anti-glaucoma Medications (AGMs) at post-operative period (POP) of 1 month and at last visit

\section{Supplementary Files}

This is a list of supplementary files associated with this preprint. Click to download.

- ESM1.pdf

- ESM2.pdf

- ESM3.pdf

- ESM4.pdf 